\title{
Extraction and Characterization of Coffee Silverskin Oil and Its Valorization by Enzymatic Hydrolysis
}

\author{
Danyelle A. Mota ${ }^{1,2}$, Anna Paula R. Silva ${ }^{1,2}$, Jefferson Cleriston B. Santos ${ }^{1,2}$, Milson S. Barbosa ${ }^{1,2}$, Lays C. Almeida ${ }^{1,2}$, \\ Álvaro S. Lima ${ }^{1,2}$, Matheus M. Pereira ${ }^{3}$, Laiza C. Krause ${ }^{1,2}$, Cleide Mara F. Soares ${ }^{1,2^{*}}$ \\ ${ }^{1}$ Tiradentes University (UNIT), Aracaju, SE; ${ }^{2}$ Institute of Technology and Research (ITP), Aracaju, SE, Brazil; ${ }^{3}$ University of \\ Aveiro, CICECO - Aveiro Institute of Materials, Department of Chemistry, Aveiro, Portugal
}

\begin{abstract}
This study investigated the coffee silverskin (CS) crude oil extraction process and characterization of physicochemical properties and enzymatic hydrolysis for fatty acids production. The soxhlet and ultrasonic extractions showed CS oil yield similar to $3.8 \%$ and $3.1 \%$, respectively. CS oil extracted by soxhlet presented favorable physicochemical properties with the quality and was used as the feedstock for fatty acids production by enzymatic hydrolysis. The porcine pancreatic lipase showed hydrolytic activity of $1156 \mathrm{U} . \mathrm{g}-1 \pm$ 13.4. Therefore, we verified the potential of application in biotransformation reactions of oils with biocatalyst with fatty acids production and valorization of coffee industry waste. Keywords: Coffee Silverskin. Crude Oil. Enzymatic Hydrolysis. Fatty Acids.

Abbreviations: CS: coffee silverskin; PPL: porcine pancreatic lipase; SE: soxhlet extraction; UE: ultrasonic extraction; SCG: spent coffee grounds.
\end{abstract}

\section{Introduction}

Coffee is one of the most consumed beverages in the world and global consumption of 161 million of $60 \mathrm{~kg}$ coffee bags per year. So, there is a production of coffee byproducts such as coffee silverskin (CS) [1-3]. The CS is the thin tegument that covers the two coffee seeds and it is the only byproduct generated during green bean roasting and represents about $4.2 \%(\mathrm{w} / \mathrm{w})$ of coffee beans. From eight tons of coffee roasted, around $60 \mathrm{~kg}$ of CS is produced [1]. Therefore, CS disposal needs to be properly managed due to the increasing coffee production and the environmental impact of waste accumulation [1-3].

Some studies on the utilization of coffee waste have been advanced worldwide $[4,5]$. CS is a

Received on 12 September 2020; revised 21 December 2020. Address for correspondence: Cleide Mara Faria Soares. Tiradentes University, Institute of Technology and Research, Av. Murilo Dantas, 300, Zip Code: 49032-971, Aracaju, SE, Brazil. Phone: +55 (79) 32182190. Fax: +55 (79) 32182190. E-mail address: cleide18@yahoo.com.br. Article selected from VI International Symposium on Innovation and Technology (SIINTEC).

J Bioeng. Tech. Appl. Health

C 2021 by SENAI CIMATEC. All rights reserved. byproduct with the potential for application in the manufacture of functional paper having a low water absorbency [5]. Furthermore, CS can be used in the cosmetics, nutrition, and health industry, from the bioactive extract [4]. However, there is a promising approach to be explored that aims at the utilization of residual CS oil. CS oil is mainly composed of linoleic and palmitic acids [6]. Fatty acids can be applied in cosmetics, lubricants, and the food industry [7]. The hydrolysis of vegetable oils is the common method for fatty acid production and the reaction can be catalyzed by enzymes.

In the past years, there has been an increased interest in the isolation and valorization of compounds from the coffee industrial waste as a possibility to avoid their loss. Based on this context, the objective of this study was the valorization of coffee silverskin wastes. CS crude oils extraction process was investigated and the characterization of physicochemical properties was performed for further enzymatic hydrolysis for fatty acids production.

\section{Material and Methods}

\section{$\underline{\text { Materials }}$}

Coffee silverskin samples were supplied by a factory, located in the city of Itabaiana-Se (Brazil). 
Hexane for oil extraction was obtained from Synth (Brazil). The porcine pancreatic lipase (PPL) was purchased from Sigma Chemical Co. (St. Louis, MO, USA). Other chemicals were of analytical grade.

\section{Methods}

\section{Extraction of Coffee Silverskin Oil}

The moisture removal of CS samples for subsequent oil extraction was accomplished via drying at approximately $60 \pm 2{ }^{\circ} \mathrm{C}$ for $24 \mathrm{~h}$ before lipid extraction.

\section{Soxhlet Extraction (SE)}

For oil extraction, we used $20 \mathrm{~g}$ of CS with $150 \mathrm{~mL}$ hexane and refluxed by $8 \mathrm{~h}$ using Soxhlet apparatus. Following an extraction, lipids remain dissolved in the solvent solution and rotary evaporation was used to rapidly remove the excess solvent by applying heat to a rotating roundbottomed flask at reduced pressure.

\section{Ultrasonic Extraction (UE)}

The ultrasonic extraction study was performed with a $20 \mathrm{~g}$ silverskin sample for 30 minutes, (3 times in sequence) with $50 \mathrm{~mL}$ of hexane. The ultrasound equipment used was Ultronique (model USC-2800), frequency $25 \mathrm{kHz}$ and power of 220 W. After each extraction of $50 \mathrm{~mL}$ of solvent, the solid fraction was separated by filtration. After the extractions were mixed, the division of the oil and solvent was by rotevaporation.

Any remaining traces of solvent were removed by nitrogen-assisted evaporation. All extraction methodologies were performed in triplicate and the yield (Equation 1) was calculated for later characterization of physicochemical properties, in which $W_{1}$ is the weight of the empty glass vial, $W_{2}$ is the weight of the vial plus the extracted oil and $W_{3}$ is the weight of the dry CS with,

$$
\% \text { oil recovered }=\frac{W 2-W 1}{W 3} \times 100
$$

\section{Physicochemical Properties}

The quality of the oil was monitored through the physicochemical properties: acid value, free fatty acid content, iodine value, saponification value, peroxide value, density, kinematic viscosity, water content, and refractive index, according to standard analytical methods recommended by Official Methods of Analysis [8].

UV specific absorbances ( $\mathrm{K}_{232}$ and $\left.\mathrm{K}_{270}\right)$ assays were carried out following the analytical methods described by the Commission Regulation of the European Union for olive and olive-pomace oils (EEC) $\mathrm{N}^{\circ} 2568 / 91$ [9].

The functional groups of oil were analyzed by Attenuated total reflection Fourier transforminfrared (ATR-FTIR) spectroscopy (AGILENT CARY 630 FTIR, Agilent Technologies, USA). ATR-FTIR measurements were performed by using approximately $5 \mu \mathrm{L}$ of oil sample on the ATR crystal plate. with a scan range from $500 \mathrm{~cm}^{-1}$ to $4000 \mathrm{~cm}^{-1}$.

\section{In silico Analysis of Pancreatic Porcine Lipase}

The open crystal structure of PPL (PDB code 1ETH) was obtained from Protein Data Bank. In silico analysis (lid identification, catalytic triad, and oxyanion hole on lipase three-dimensional structure) was performed using the BIOVIA Discovery Studio software [10].

Fatty Acid Production by Enzymatic Hydrolysis of Coffee Silverskin Oil

The enzymatic hydrolytic activity of free lipase was measured by the titration of the fatty acid which comes from the hydrolysis of CS residual oil [11]. The substrate was constituted by $50 \mathrm{~mL} \mathrm{CS}$ crude oil with $50 \mathrm{~mL}$ gum arabic solution $(3 \%$ $\mathrm{w} / \mathrm{v})$ and the addition of Triton X-100 (18\%). The hydrolytic activity of the biocatalysts was determined according to Equation 2, in which one unit (U) of activity was defined as the amount of enzyme that liberates $1 \mu \mathrm{mol}$ free fatty acids per min $\left(\mu \mathrm{mol} \cdot \mathrm{min}^{-1}\right)$ under the assay conditions. 
Hydrolytic Activities (U.g $\left.{ }^{-1}\right)=\frac{\left(V_{A}-V_{B}\right) \times N \times 10^{3}}{t \times m}$

$V$ A corresponds to the volume of $\mathrm{KOH}$ spent in the titration of the sample $(\mathrm{mL}), V_{\mathrm{B}}$ is the volume of the $\mathrm{KOH}$ spent in the titration of the blank (mL), $N$ is the normality of the $\mathrm{KOH}$ solution, $t$ is the reaction time in minutes and $m$ is the mass of free $(\mathrm{g})$.

\section{Results and Discussion}

\section{Extraction of Coffee Silverskin Oil}

Figure 1 described the results of CS oil yield extractions by different methods (SE and UE). The soxhlet extraction using hexane presented $3.8 \%$ of extracted lipids, while ultrasonic extraction 3.1\% (no significant differences; $\mathrm{p} \geq 0.05$ ). The yield lipid of the silverskin analyzed in this study was complete following the values with the literature, between 2.4-3.4\% [3,12]. The variation found in CS lipid content can be partially attributed to factors such as the different blends of coffee varieties, the origin of the coffee beans, and the processing. However, the oil extracted by soxhlet was shown to have a physical aspect (viscosity, coloring) more suitable for future applications. On the other hand, the oil obtained from ultrasoundassisted extraction was affected due to shear forces generated by the ultrasound cavitations. So, cell wall ruptures occurred, increasing the contact area between the solvent and the materials, intensifying the general oil extraction process and other compounds [13]. Considering the yields and quality of the extracted oil, the soxhlet extraction was selected as the most promising for the characterization of physicochemical properties and hydrolysis of the crude oil.

\section{$\underline{\text { Physicochemical Properties }}$}

Table 1 presented the physicochemical properties related to the quality of the crude CS oil. However, in the literature, there is the characterization of the physicochemical properties of oil from other residues from coffee processing, as the spent coffee grounds (SCG) (Table 1). The acid value of CS oil was $13.5 \mathrm{mgKOH} / \mathrm{g}$, an important quality parameter related to the extent of oil degradation by hydrolysis, releasing free fatty acids [14]. The iodine index was responsible for expressing the degree of oil unsaturation by breaking the double bonds and then the iodine is inserted and is directly related to its oxidative stability [15]. The analyzed saponification index was $158.3 \mathrm{mgKOH} / \mathrm{g}$, just below the expected range for vegetable oil (180 and $200 \mathrm{mgKOH} / \mathrm{g}$ ). The relatively low levels of saponified matter mean that the oil remains viscous and does not freeze easily, making it suitable for applications in oil transformation [14]. The peroxide value was

Figure 1. Extraction yield from coffee silverskin oil by soxhlet extraction and ultrasonic extraction.

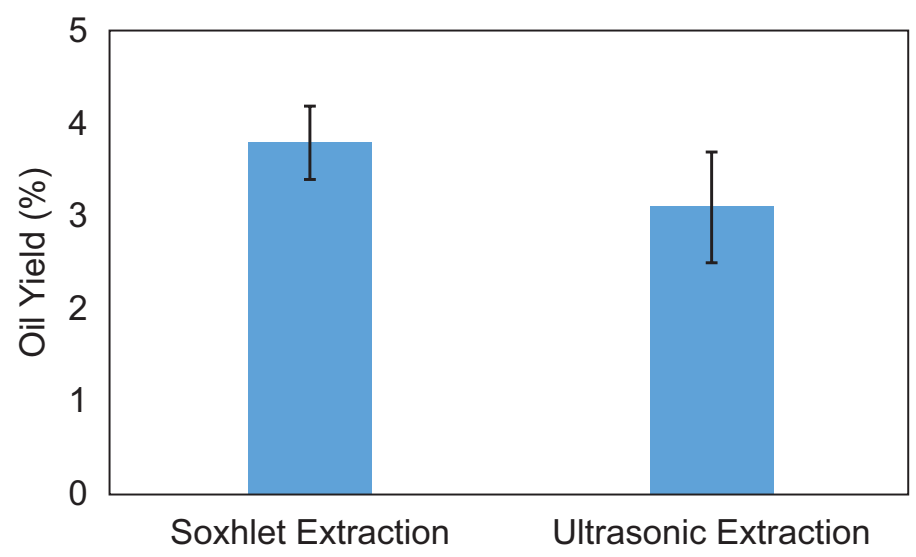


$5.9 \mathrm{meqO}_{2} / \mathrm{kg}$, which indicates high resistance to oxidation of CS oil, and that it can be stored for longer [15]. Density at $40{ }^{\circ} \mathrm{C}$ amounted to $0.90 \mathrm{~g} / \mathrm{cm}^{3}$ and kinematic viscosity at $40{ }^{\circ} \mathrm{C}$ was $73.5 \mathrm{~mm}^{2} / \mathrm{s}$. The unsaturated oils have higher densities than those saturated oils. The refraction index at $40{ }^{\circ} \mathrm{C}$ was 1.46 , in which a larger hydrocarbon chain will deflect a greater amount of light, resulting in greater refraction. The content of water in oil was $0.6 \%$. The determination of oil moisture is important, as water favors the growth of microorganisms and product degradation. The low values of $\mathrm{K}_{232}$ and $\mathrm{K}_{270}$ in both crude CS oil indicated a low extent of oxidation. For crude oils, $\mathrm{K}_{232}$ is related to the first stage of oxidation with the presence of conjugated hydroperoxides, while $\mathrm{K}_{270}$ is related to the presence of secondary oxidation products, like aldehydes, ketones, and short-chain fatty acids [16].

Figure 2 shows the FTIR spectrum used to analyze the main functional groups present in the silverskin oil. The absence of a peak after $3000 \mathrm{~cm}^{-1}$ indicates very low concentrations of impurities contained in hydroxyl groups $(\mathrm{OH})$, such as free glycerol and water, which corroborates the moisture data $(0.6 \%)$ obtained in this study. The two intense bands at $2852 \mathrm{~cm}^{-1}$ and $2924 \mathrm{~cm}^{-1}$ were due to $\mathrm{CH} 2$ asymmetric and symmetric stretching vibrations, attributed to the fatty acids present in the oil. Peaks between $722 \mathrm{~cm}^{-1}$ and $1466 \mathrm{~cm}^{-1}$ are associated with various $\mathrm{CH}$ groups. The bending of cis $\mathrm{C}=\mathrm{C}$ was observed at peak $722 \mathrm{~cm}^{-1}$, the vibration of $-\mathrm{C}-\mathrm{O}$ ester groups which corresponded to the large area at peak $1158 \mathrm{~cm}^{-1}$ and $\mathrm{C}=\mathrm{O}$ stretching related to peak $1720 \mathrm{~cm}^{-1}$ [17].

In silico Characterization of Pancreatic Porcine Lipase (PDB: XX) and Potential Application in Hydrolysis of Coffee Silverskin Oil

PPL is a protein with $50 \mathrm{kDa}$ and a specific sequence of 449 amino acids that play a key role in PPL specificity (Figure 3A). Figure 3B presents the three-dimensional structure of PPL has an $\alpha$-helical flexible lid (constituted by amino acids between 237 and 261, in red). In closed conformation, the flexible lid covers the enzyme catalytic triad (inactive state). On the other hand, PPL open conformation is based on lid movement exposing the amino acid from enzyme catalytic triad, Serine 153, Aspartic acid 177, and Histidine 264 (Figure 3C), to interact with substrates in organic media and the water/lipid interfaces. The amino acid residues, Phenylalanine 78 and Leucine 154 (PPL oxyanion hole), play a significant role in

Table 1. Physicochemical properties of oil extracted from coffee silverskin.

\begin{tabular}{lccc}
\hline Properties & $\begin{array}{c}\text { Determined } \\
\text { values }\end{array}$ & $\begin{array}{c}\text { Haile et al. [15] } \\
\text { SCG }\end{array}$ & $\begin{array}{c}\text { Al-Hamamre et al. [14] } \\
\text { SCG }\end{array}$ \\
\hline Acid value $(\mathrm{mgKOH} / \mathrm{g})$ & $13.5 \pm 0.2$ & 9.8 & 7.3 \\
Free fatty acid $(\mathrm{mgKOH} / \mathrm{g})$ & $6.7 \pm 0.2$ & 4.9 & 3.6 \\
Iodine value $(\mathrm{gI} / \mathrm{l00 \textrm {g } )}$ & $74.6 \pm 2.8$ & 79 & $\mathrm{ND}$ \\
Saponification value $(\mathrm{mgKOH} / \mathrm{g})$ & $158.3 \pm 1716$ & 7.3 & 173.9 \\
Peroxide value $(\mathrm{meqO} / \mathrm{kg})$ & $5.9 \pm 0.3$ & $\mathrm{ND}$ & $\mathrm{ND}$ \\
Density at $40{ }^{\circ} \mathrm{C}\left(\mathrm{g} / \mathrm{cm}^{3}\right)$ & 0.90 & 0.92 & 0.92 \\
Kinematic viscosity at $40{ }^{\circ} \mathrm{C}\left(\mathrm{mm}^{2} / \mathrm{s}\right)$ & 73.5 & 42.6 & 55.5 \\
Refractive index & $1.46 \pm 0.003$ & $\mathrm{ND}$ & $\mathrm{ND}$ \\
$\mathrm{Water} \mathrm{content}(\%)_{\mathrm{K}_{232}}$ & $0.6 \pm 0.3$ & 0.03 & $\mathrm{ND}$ \\
$\mathrm{K}_{270}$ & $0.26 \pm 0.004$ & $\mathrm{ND}$ & $\mathrm{ND}$ \\
\hline
\end{tabular}

Values are mean $\pm \mathrm{SD}$ of triplicate determinations. $\mathrm{ND}=$ not determined. 
Figure 2. FTIR spectra of extracted silverskin oil.

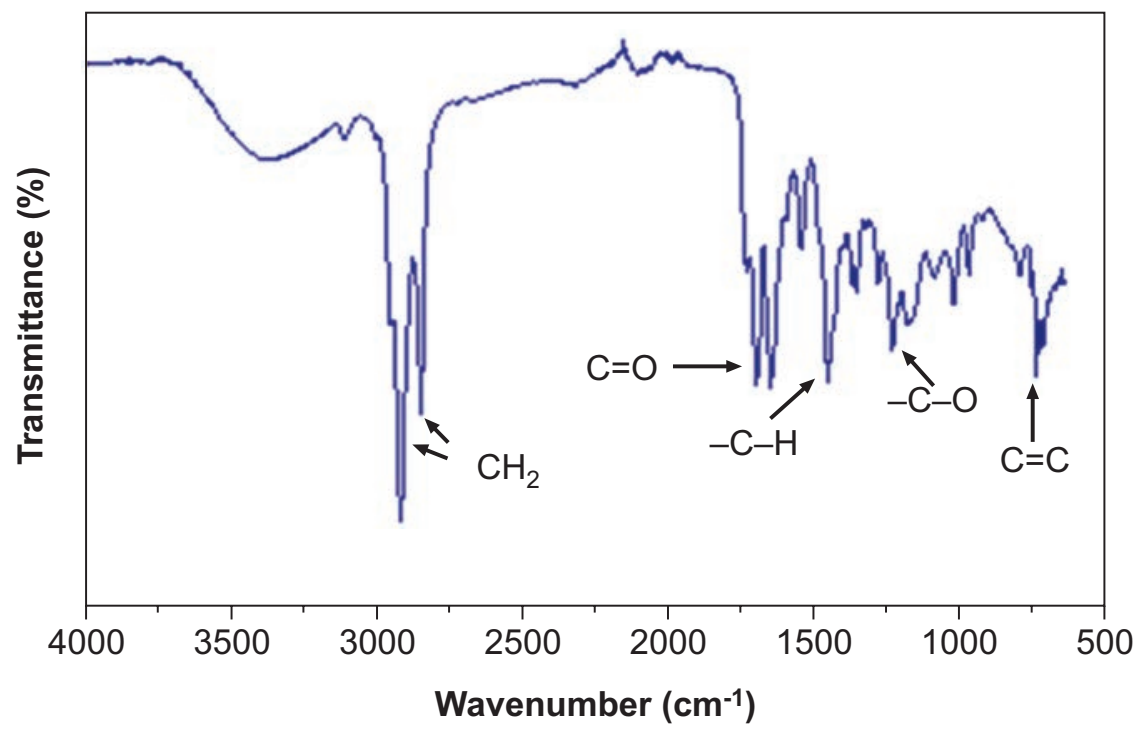

Figure 3. (A) Three-dimensional structure of pancreatic porcine lipase (PPL; PDB code 1ETH), (B) Lid of PPL (237-261, in red), (C) Catalytic triad of PPL (Serine 153, Aspartic acid 177 and Histidine 264, in green), and (D) oxyanion hole of PPL (Phenylalanine 78 and Leucine 154).

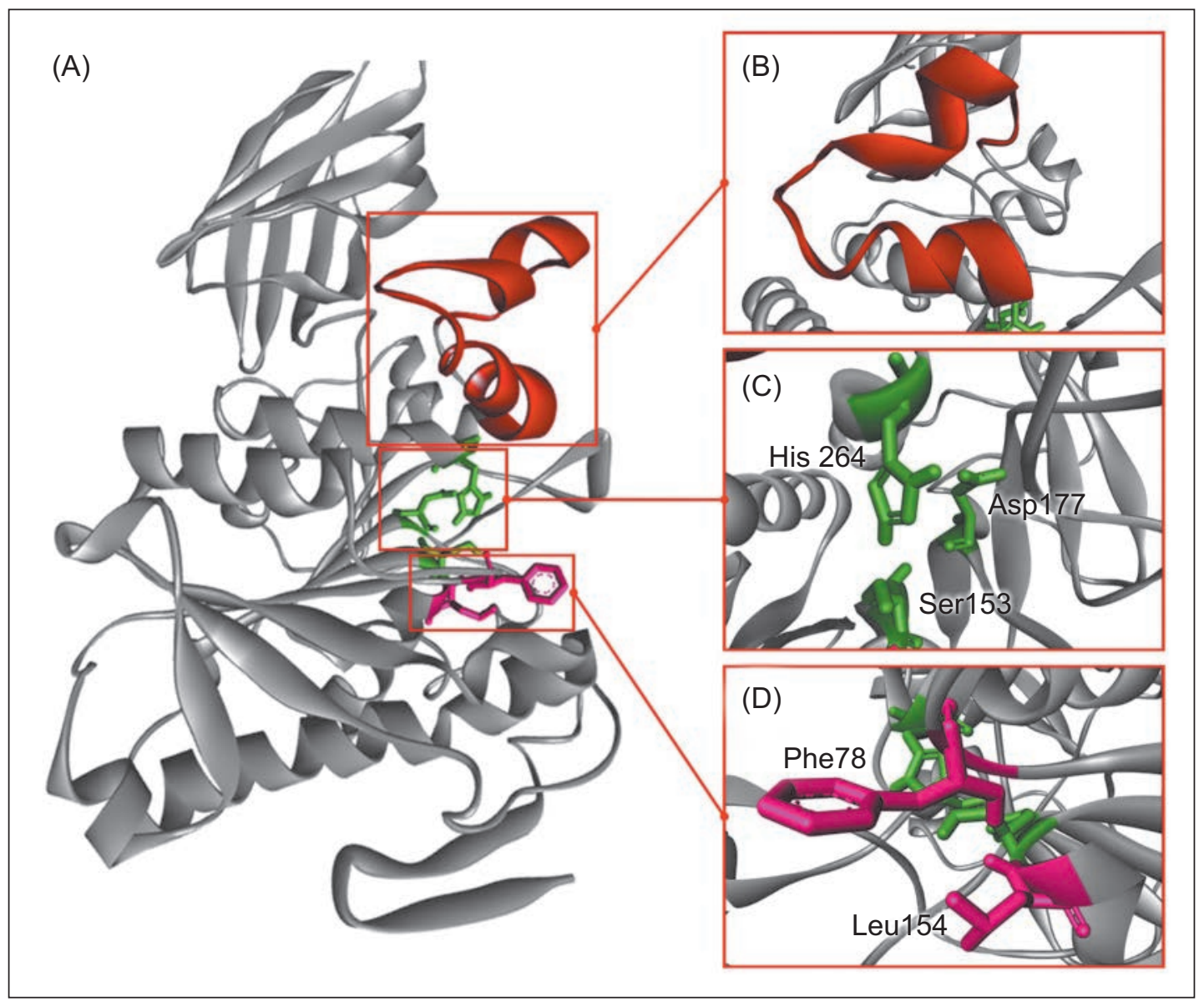


lipase catalysis reaction, stabilizing the negatively charged tetrahedral intermediates by hydrogen bonds with substrates (Figure 3D) [18].

The crucial requirement to produce fatty acids by enzymatic hydrolysis is biocatalyst hydrolytic activity. PPL is an $s n-1,3$ regiospecific lipase that preferentially catalyzes positions 1 and 3 of triacylglycerides in hydrolysis reaction $[19,20]$. Thus, PPL was used as a biocatalyst for biotransformation of CS oil by enzymatic hydrolysis, showing the hydrolytic activity of

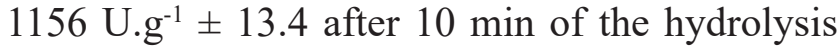
reaction. Based on these results, PPL showed to be an effective and sustainable biocatalyst to obtaining fatty acids from CS oil, a bioproduct of interest to many industrial sectors, such as food, pharmaceutical, cosmetic, and fuel.

\section{Conclusion}

Based on the results, and considering the energy matrix and utilization of the coffee silverskin with residual oil, a potential of application in biotransformation reactions of crude oils was verified with favorable physicochemical properties for the application, with the conversion of food byproducts into value-added products.

\section{Acknowledgements}

The authors acknowledge the financial support from Fundação de Apoio à Pesquisa e à Inovação Tecnológica do Estado de Sergipe (FAPITEC) and Conselho Nacional de Desenvolvimento Científico e Tecnológico (CNPq). D. A. M. acknowledges the $\mathrm{PhD}$ grant (88882.176405/2018-01) and the financial support from Coordenação de Aperfeiçoamento de Pessoal de Nível Superior (CAPES).

\section{References}

1. Alves RC, Rodrigues F, Nunes MA, Vinha AFO. State of the art in coffee processing by-products. In Handbook of Coffee Processing By-Products Sustainable. Nikki Levy 2017:1-22.
2. Costa CM, Osório NM, Canet A, Rivera I, Sandoval G, Valero F, Ferreira-Dias S. Production of MLM type structured lipids from grapeseed oil catalyzed by non-commercial lipases. Eur. J. Lipid Sci. Technol. 2018;120:1-8.

3. Costa ASG, Alves RC, Vinha AF, Barreira SVP, Nunes MA, Cunha LM, Oliveira MBPP. Optimization of antioxidants extraction from coffee silverskin , a roasting by-product, having in view a sustainable process. Ind. Crop. Prod. 2014;53:350-357.

4. Bilbao MDDC, Ezequiel MEI, Benavent MA, Calleja MH, Moral MP Del, Artiz MU. Application of products of coffee silverskin antiaging cosmetics and functional food. 2013.

5. Sato ST, Morikawa SH. Silver skin-containing paper and method for producing the same. 2011.

6. Costa ASG, Alves RC, Vinha AF, Costa E, Costa CSG, Nunes MA, Almeida AA, Santos-Silva A, Oliveira MBPP. Nutritional, chemical and antioxidant / prooxidant profiles of silverskin, a coffee roasting byproduct. Food Chem. 2018;267:28-35.

7. Hayes DG. The catalytic activity of lipases toward hydroxy fatty acids - A review. JAOCS, J. Am. Oil Chem. Soc. 1996;73:543-549.

8. AOAC Official Methods of Analysis. Assoc. Off. Agric. Chem. 1990:1.

9. Commission Regulation (EEC) Official Journal of the European Communities. Off. J. Eur. Communities 1991, $2568 / 91$.

10. BIOVIA Dassault Systèmes, Discovery Studio Visualizer, v20.1.0.19295, San Diego: Dassault Systèmes. 2020.

11. Soares CMF, De Castro HF, De Moraes FF, Zanin GM. Characterization and utilization of Candida rugosa lipase immobilized on controlled pore silica. Appl. Biochem. Biotechnol. - Part A Enzym. Eng. Biotechnol. 1999:77-79, 745-757.

12. Toschi TG, Cardenia V, Bonaga G, Mandrioli M, Rodriguez-Estrada MT. Coffee silverskin : Characterization, possible uses, and safety aspects. J. Agric. Food Chem. 2014;62:10836-44.

13. Efthymiopoulos I, Hellier P, Ladommatos N, Kay A, Mills-Lamptey B. Effect of solvent extraction parameters on the recovery of oil from spent coffee grounds for biofuel production. Waste and Biomass Valorization 2019;10:253-264.

14. Al-hamamre Z, Foerster S, Hartmann F, Kröger M, Kaltschmitt M. Oil extracted from spent coffee grounds as a renewable source for fatty acid methyl ester manufacturing. Fuel 2012;96:70-76.

15. Haile M. Integrated volarization of spent coffee grounds to biofuels. Biofuel Res. J. 2014;2:65-69.

16. Sonntag NOV. New developments in the fatty acid industry. J. Am. Oil Chem. Soc. 1979;56:861 A-864A. 
17. Goh BHH, Ong HC, Chong CT, Chen W-H, Leong KY, Tan SX, Lee XJ. Ultrasonic assisted oil extraction and biodiesel synthesis of Spent Co ff ee Ground. Fuel 2020;261:116-121.

18. Hermoso J, Pignol D, Kerfelec B, Crenon I, Chapus C, Fontecilla-Camps JC. Lipase activation by nonionic detergents. J. Biol. Chem. 1996;271:18007-18016.
19. Kapoor M, Gupta MN. Lipase promiscuity and its biochemical applications. Process Biochem. 2012;47:555-569.

20. Mota DA, Rajan D, Heinzl GC, Osório N, Gominho $\mathrm{J}$ et al. Production of low-calorie structured lipids from spent coffee grounds or olive pomace crude oils catalyzed by immobilized lipase in magnetic nanoparticles. Bioresour. Technol. 2020;307: 123-223. 